DOI:

\title{
Head Nurses' Attitude and Preparedness Regarding Delegation and its Relation to Their Performance at Benha University Hospital
}

\author{
Marwa A. Ramzy ${ }^{1}$, Karima A. Elsayed ${ }^{2}$ and Ehsan S. Soliman ${ }^{3}$ \\ ${ }^{1}$ Bsc. Nursing, Tanta University, ${ }^{2}$ Assistant professor of Nursing Administration, Tanta \\ University, ${ }^{3}$ Lecturer of Nursing Administration, Benha University
}

\begin{abstract}
Delegation is the assignment of authority to another person to carry out specific activities and to make decisions and complete specific tasks. Delegation is a vital skill to help head nurses spend their time in the most productive ways, save time and perform their duties better. The purpose of the study was to assess head nurses' attitude and preparedness regarding delegation and its relation to their performance at Benha University Hospital. Design: descriptive design was utilized in carrying out this study. Setting: the study was conducted in all departments at Benha University Hospital. Study Sample: all available 110 head nurses were included. Two instruments were used for data collection of this study (self-administered questionnaire for head nurses' attitudes and preparedness regarding delegation and observational checklist of head nurses' performance regarding delegation). Results: indicated that about half of head nurses $(51.8 \%)$ had a positive attitude, the majority $(90.9 \%)$ of head nurses had high preparedness regarding delegation, the majority $(86.4 \%)$ of head nurses' performance regarding delegation was satisfactory and there was a highly statistically positive correlation between head nurses' attitude, preparedness, and performance regarding delegation. Recommendations: Workshops should be held to raise head nurses' awareness about delegation and performance regarding delegation.
\end{abstract}

Keywords: Delegation, Head nurses, Attitude, Preparedness, Head nurses' performance

\section{Introduction}

Delegation is the assignment of authority to another person to carry out specific activities and to make decisions and complete specific tasks. Delegating appropriate tasks to staff can be effective method to ensure high-quality care and good patient outcomes (American Nurses Association, 2017).

Delegation is a complex process in professional practice, requiring advanced clinical judgment and accountability for patients 'care. The reality is that delegating is a necessary skill in nursing practice today due to nursing shortages, rising patient acuity, and the new emphasis on patient satisfaction. Delegation is a vital skill to help head nurses spend their time in the most productive ways, delegation can save time, can give them the ability to perform their duties better and build valuable skills in those they delegate to, making it easier to delegate to them in the future (Engard, 2017).

Head nurses lead teams and are responsible for the nursing process and outcomes for patient care this require delegation skills because delegation is one of the key factors in effective team work (Kaernested and Bragadóttir, 2012). For effective delegation, head nurses need to be aware of staff's legal job definitions and job descriptions, as well as their skills and willingness to accept the delegation (Zakaria, 2016). Successful delegation is influenced by various factors including effective communication, collaborative work relationship, level of competence and knowledge and role clarity. Head nurses need to work effectively with the staff through having the abilities to delegate, assign, and supervise (National Council of State Boards of Nursing, 2016). 


\section{Head Nurses' Attitude and Preparedness Regarding Delegation and its Relation to Their Performance at Benha University Hospital}

One study carried out in Saudi Arabia found Lack of delegation is one of the most common stressors; leading to work stress and turnover (Gassas et al ., 2017). Delegation of authorities is partially practiced, some personnel fear to delegate due to personal perception, and subordinates fear to be delegated since they fail to understand what is to be done on the issue of delegation (Swai , 2014). Head nurses spend more time working on those activities which have no professional knowledge, when they do not delegate their tasks to subordinates (Sayani, 2016).

Some head nurses believe that the time is lost by delegating tasks and fear that a task delegated won't be performed to their high standards (Innes, 2017).A major reason for managerial failure is poor delegation of authority. The problem isn't a lack of understanding about what delegation actually but is with personal attitudes toward delegation on the part of managers, these attitudes that make it impossible for delegation to be successful (Demers, 2015). The process of delegation is an art, to be effective the head nurse need to perform some steps as the following; define the task, select the most capable person, assess ability and training needs, explain the reasons, state required results, consider resources required, agree deadlines, support and communicate feedback on happened results (Clement, 2016).

It is very important as a head nurse to consider all aspects that go into delegating tasks to others. When all the guidelines are followed correctly a good judgment is used when good choosing who to delegate a task, delegation can be a great tool that nurses can use. To give more efficiently care for their patients, it is most importance that head nurse put the care and needs of the patients first when making decisions that could affect their treatment and ultimately their lives (Hughes, 2017) .

\section{Purpose of the study}

To assess head nurses' attitude and preparedness regarding delegation and its relation to their performance at Benha University Hospital.

\section{Research questions}

The research questions are the following:

1- What are the attitudes of head nurses' regarding delegation?

2- To what extent are head nurses prepared to delegate effectively?

3- What is level of head nurses' performance?

4- Are there associations among head nurses' attitude \& preparedness regarding delegation and their performance?

\section{Methods}

Study design: A descriptive correlational design was used in carrying out the study.

Setting: The study was conducted at Benha University Hospital.

Sampling: This study included all (110) available head nurses at Benha University Hospital at the time of study.

Instruments: Data of the present study was collected by using two instruments:

Instrument one: Self-administered questionnaire for head nurses' attitudes and their preparedness regarding delegation: This instrument was developed by Kaernested and Bragadóttir (2012). It was used to assess head nurses' attitude and preparedness regarding effective delegation. It consisted of two parts:-

First part: It included personal characteristics of head nurses as age, educational qualification, years of experience, and years of experience in present nursing unit /department, marital status and attended training courses.

Second part: It consisted of head nurses' attitude regarding delegation which 


\section{Head Nurses' Attitude and Preparedness Regarding Delegation and its Relation to Their Performance at Benha University Hospital}

contained (14 items), and head nurses preparedness regarding delegation consists of two subscale, subscale one a geared toward principles and rights of delegation contained (13 items) subscale two, reflected head nurses' preparedness to delegation, it contained (10 items).

Scoring system for head nurses' attitude:

\begin{tabular}{|l|c|}
\hline Scoring items & Score \\
\hline Strongly disagree & 1 \\
\hline Disagree & 2 \\
\hline Uncertain & 3 \\
\hline Agree & 4 \\
\hline Strongly agree & 5 \\
\hline
\end{tabular}

Scoring system for head nurses' preparedness:

\begin{tabular}{|l|c|}
\hline $\begin{array}{l}\text { Scoring items for } \\
\text { subscale one }\end{array}$ & Score \\
\hline Never & 1 \\
\hline Sometimes & 2 \\
\hline Always & 3 \\
\hline
\end{tabular}

\begin{tabular}{|l|c|}
\hline $\begin{array}{l}\text { Scoring items for } \\
\text { subscale two }\end{array}$ & Score \\
\hline Disagree & 1 \\
\hline Unsure & 2 \\
\hline Agree & 3 \\
\hline
\end{tabular}

Instrument two: Observational checklist of head nurses' performance regarding delegation process. It was developed by Mikhemer (2016). It was used to assess performance of head nurses regarding delegation process. It consisted of two parts: -

First part: It included personal characteristic as age, department and years of experience.

Second part: It included 55 items divided into 7 skills; selection and organization of the task (5 items), selection of appropriate person (6 items), explanation of the expectations to delegate (6 items), degree of responsibility, authority and accountability with delegate(5 items), maintenance control and supervision (10 items), evaluation and following up( 9 items) and delegate and not delegate (14 items).

\section{Scoring system:}

\begin{tabular}{|l|c|}
\hline \multicolumn{1}{|c|}{ Scoring items } & score \\
\hline Not done & 0 \\
\hline Done incompletely & 1 \\
\hline Done completely & 2 \\
\hline
\end{tabular}

\section{Procedure:}

1- An official permission was taken from the dean of the faculty of nursing and approval was taken from the director of Benha University Hospital.

2- The data collection instrument was developed after a review of available literature concerning with the topic of the study using books, scientific thesis, articles, exploring internet and periodical magazines to obtain instruments for data collection and write a review of literature for this study.

3- Content validity: Instruments content validity was done by five experts in the related field to check the relevancy, clarity, comprehensiveness, and applicability of the tools of data collection. Jury experts involved four assistant professors of nursing administration working at Ain-Shams University and one lecturer of nursing administration working at Benha University . According to experts' opinions, minor modifications were done and the final form was prepared.

4- The reliability of instruments of data collection done by using the Cronbach's Alpha test for measure the internal consistency of the study result. Result equal, attitude reliability was 


\section{Head Nurses' Attitude and Preparedness Regarding Delegation and its Relation to Their Performance at Benha University Hospital}

(0.78), preparedness reliability was $(0.874)$ and performance reliability was $(0.826)$.

5- A Pilot study was done on $10 \%$ of the total subjects, they were (11) participants. Data which obtained from the pilot study were analyzed. As a result of the pilot study, not modification is done and items were understandable. The time needed to fill the questionnaire was about (10- 15) minutes. The subjects who participated in the pilot study were included in the study sample.

6- For ethical consideration an oral acceptance was obtained from head nurses after clarifying the aim of the study. Privacy and confidentiality of the study participants' data were assured. Participation in the study is voluntary and participants were assured that withdrawing from the study at any stage without responsibility.

7- The actual data collection took about three months from September to end of November 2017.

8- Data analysis: Data analysis was performed using SPSS statistical software version 22. The data were explored. Descriptive statistics with mean and standard deviation (SD) for continuous variables and frequency for categorical variables were analyzed. Qualitative variables were compared using qui square test $\left(\mathbf{X}^{\mathbf{2}}\right)$ as the test of significance, independent $(\mathrm{t})$ test and ANOVA test was used to compare mean score between two and more groups respectively. Correlation coefficient (r) was used to evaluate association between studied variables .The p-value is the degree of significant. A significant level value was considered when $\mathrm{p}$-value $\leq 0.05$ and a highly significant level value was considered when $p$-value $\leq 0.001$, while p-value > 0.05 indicates nonsignificant results.

\section{$\underline{\text { Results }}$}

Table ( 1 ) clarifies that more than two thirds $(69.1 \%)$ of head nurses aged more than 30 years and more than three quarters $(83.6 \%)$ of them had bachelor degree in nursing .In relation to years of experience more than one quarter $(30.9 \%)$ of head nurses had more than 15 years of experience .As regards to marital status, the majority $(90.9 \%)$ of them were married. The majority $(85.5 \%)$ of them had received training course.

Figure (1) reveals that more than half $(51.8 \%)$ of head nurses had positive attitude. While less than half $(48.2 \%)$ of them had uncertain attitude.

Table (2) illustrates that the principles of head nurses regarding delegation was with mean scores $34.4 \pm 3.2$ and preparedness of head nurses regarding delegation was with mean scores 28.54 .

Figure (2) reveals that the majority $(90.9 \%)$ of head nurses had high level of preparedness regarding delegation process.

Table (3) clarifies that the head nurses when not delegate had maximum scores (27) with mean scores $24.7182 \pm 3.20588$. As regard to head nurses' performance regarding select and organize the task had minimum scores 6.00 with mean $9.4727 \pm$ .83181 and head nurses' performance regarding select appropriate person had minimum scores 6.00 with mean 8.2455.

Figure (3) reveals that the majority $(86.4 \%)$ of head nurses were satisfactory performance, while the minority $(13.6 \%)$ of them were unsatisfactory performance.

Table (4) shows that there were no statistical significant differences between characteristics of head nurses and attitude regarding delegation process expect for educational qualification ( $p<0.05$ 


\section{Head Nurses' Attitude and Preparedness Regarding Delegation and its Relation to Their Performance at Benha University Hospital}

Table(5) shows that there were no statistical significant differences between head nurses' characteristics and preparedness regarding delegation process $(\mathrm{P}=>0.05)$.

Table (6) shows there were no statistical significant difference between head nurses' characteristics and their performance regarding delegation process $(\mathrm{P}=>0.05)$.

Table (7) clarifies that there was a high statistical significant relation between head nurses' attitude, preparedness and performance regarding delegation process and their working years of experience.

Table (8) clarifies that there was a highly statistically significant correlation between head nurses' attitude, preparedness and performance regarding delegation process $(\mathrm{p}=.000)$.

Table (1): Characteristics of the studied subjects $(n=110)$

\begin{tabular}{|c|c|c|}
\hline Characteristics & Frequency & $\%$ \\
\hline \multicolumn{3}{|l|}{ Age in years } \\
\hline $20-25$ & 5 & 4.5 \\
\hline $26-30$ & 29 & 26.4 \\
\hline$>30$ & 76 & 69.1 \\
\hline \multicolumn{3}{|l|}{ Mean \pm SD } \\
\hline \multicolumn{3}{|l|}{ Educational qualification } \\
\hline Secondary degree in nursing & 10 & 9.1 \\
\hline Technical degree in nursing & 3 & 2.7 \\
\hline Bachelor degree in nursing & 92 & 83.6 \\
\hline Postgraduate & 5 & 4.5 \\
\hline \multicolumn{3}{|l|}{ Years of experience } \\
\hline $1-<5$ & 21 & 19.1 \\
\hline $5-<10$ & 22 & 20.0 \\
\hline $10-<15$ & 33 & 30.0 \\
\hline$>15$ & 34 & 30.9 \\
\hline \multicolumn{3}{|l|}{ Marital status } \\
\hline Single & 6 & 5.5 \\
\hline Married & 100 & 90.9 \\
\hline divorced & 2 & 1.8 \\
\hline Widow & 2 & 1.8 \\
\hline \multicolumn{3}{|l|}{ Training course } \\
\hline Yes & 94 & 85.5 \\
\hline No & 16 & 14.5 \\
\hline
\end{tabular}


Head Nurses' Attitude and Preparedness Regarding Delegation and its

Relation to Their Performance at Benha University Hospital

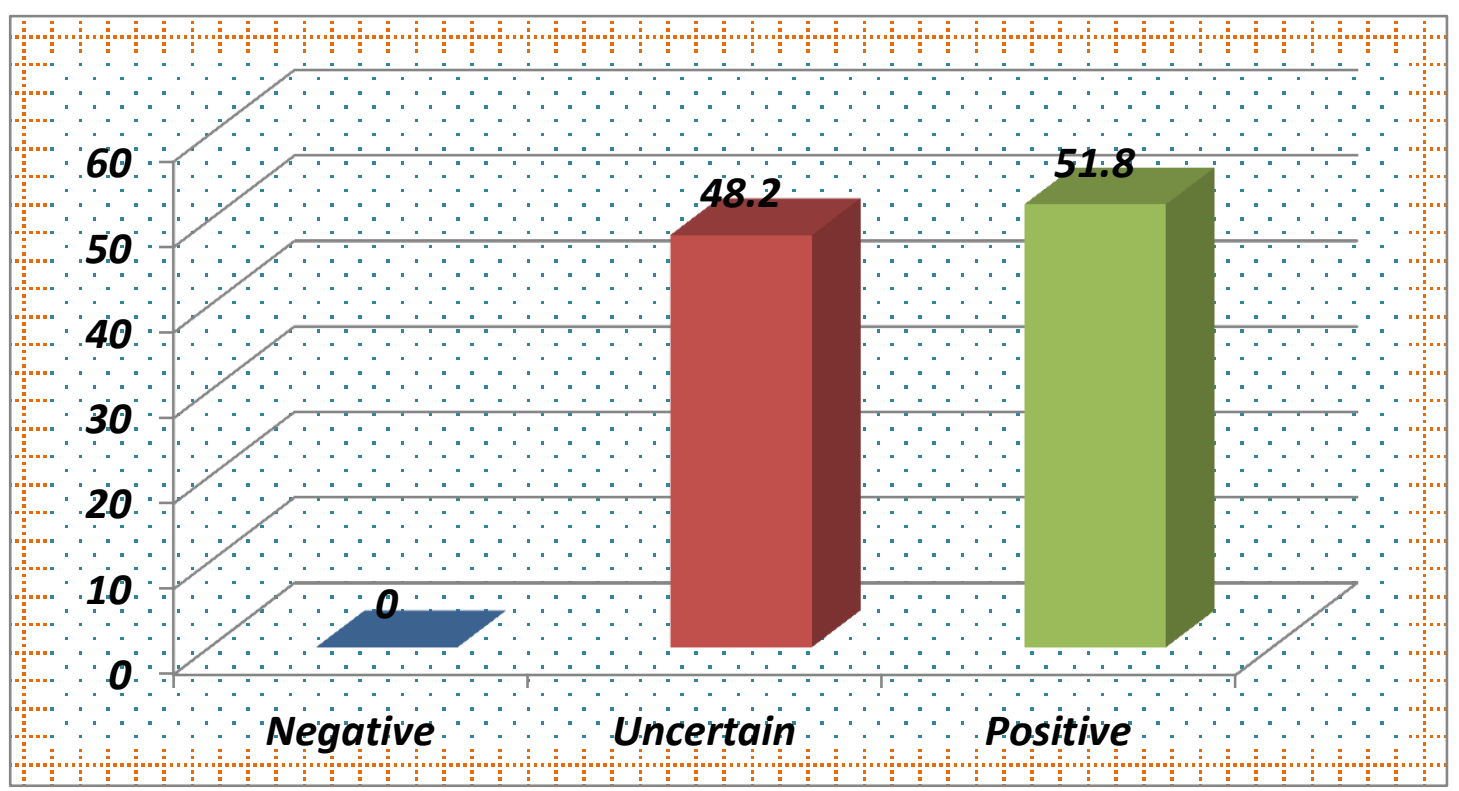

Figure (1): percentage distribution of attitude scores among the head nurses regarding delegation process.

Table (2): Distribution mean scores of the head nurses ' regarding preparedness for delegation $(\mathrm{n}=110)$

\begin{tabular}{||c|c|c|c|c||}
\hline Preparedness & Mean & Std. Deviation & Minimum & Maximum \\
\hline Principles & 34.4182 & 3.26050 & 25.00 & 39.00 \\
\hline Preparedness & 28.5455 & 2.27324 & 20.00 & 30.00 \\
\hline Total preparedness & 62.9636 & 4.61535 & 48.00 & 69.00 \\
\hline
\end{tabular}

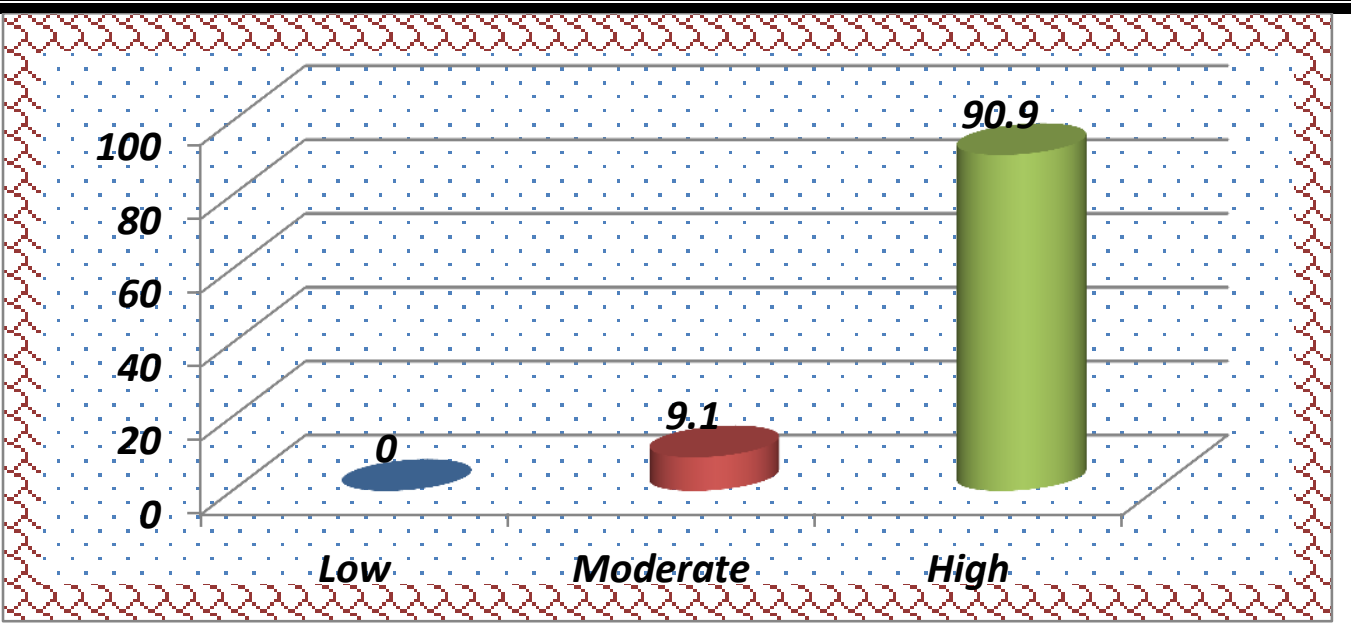

Figure (2): percentage distribution of preparedness scores between head nurses regarding delegation process

Table (3): Distribution mean scores of head nurses' performance regarding delegation

$$
(n=110)
$$


Head Nurses' Attitude and Preparedness Regarding Delegation and its Relation to Their Performance at Benha University Hospital

\begin{tabular}{|l|c|c|c|c|c||}
\hline \multicolumn{1}{|c|}{ Practice } & No of items & Mean & Std. Deviation & Minimum & Maximum \\
\hline Select and organize the task & 5 & 9.4727 & .83181 & 6.00 & 10.00 \\
\hline Select appropriate person & 6 & 8.2455 & .51020 & 6.00 & 9.00 \\
\hline Explanation of the expectations to delegate: & 6 & 4.9487 & 1.82816 & .00 & 11.00 \\
\hline Maintenance control and supervision: & 5 & 7.3182 & 1.21860 & .00 & 8.00 \\
\hline Evaluation and following up: & 10 & 9.6909 & 2.14496 & .00 & 14.00 \\
\hline When delegate & 9 & 5.6455 & 2.60411 & .00 & 12.00 \\
\hline When not Delegate & 14 & 24.7182 & 3.20588 & .00 & 27.00 \\
\hline Total practice score & 55 & 70.3545 & 6.77094 & 19.00 & 89.00 \\
\hline
\end{tabular}

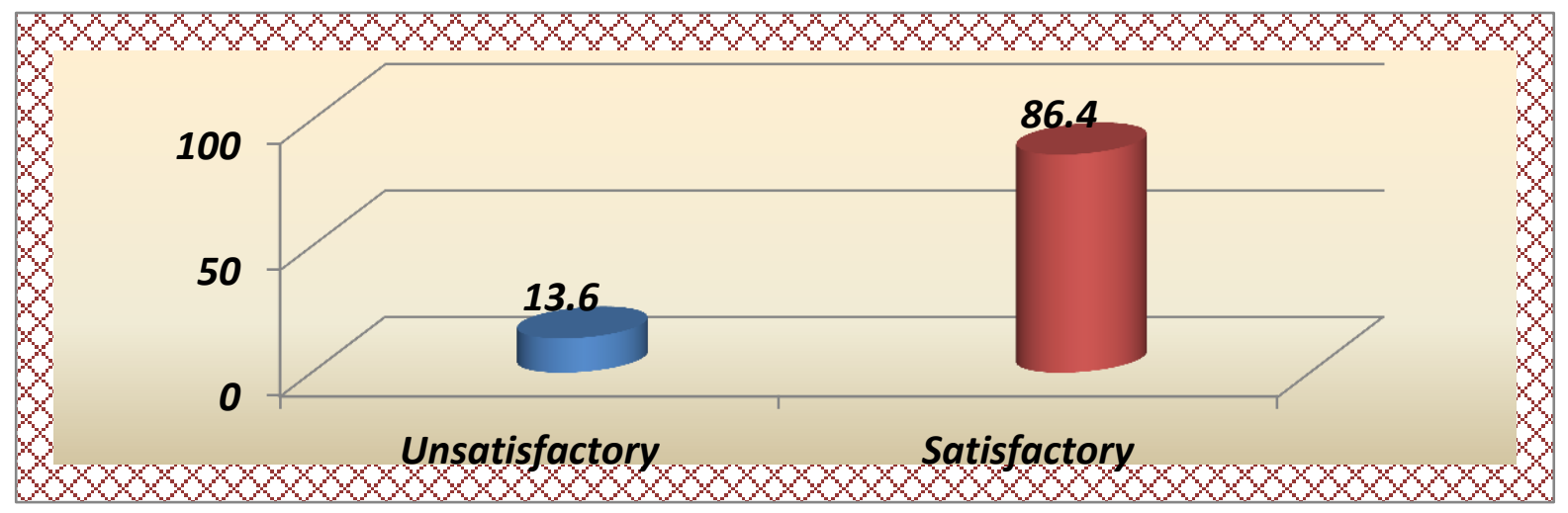

Figure (3): percentage distribution of performance scores among head nurses regarding delegation process

Table (4): Associative relation between head nurses' characteristics and their attitude scores regarding delegation process $(\mathrm{n}=110)$

\begin{tabular}{|l|c|c|c|}
\hline \multicolumn{1}{|c|}{ Characteristics } & Mean \pm SD & F test & \multirow{2}{*}{ P value } \\
\cline { 1 - 2 } Age in years & & \multirow{2}{*}{$>0.79$} \\
\cline { 1 - 2 } $20-25$ & $37.8000 \pm 2.58844$ & & \\
\cline { 1 - 2 } $26-30$ & $36.9310 \pm 3.57502$ & & \multirow{2}{*}{2.77} \\
\cline { 1 - 2 }$>30$ & $35.3947 \pm 4.68495$ & \multirow{2}{*}{$<0.05^{*}$} \\
\cline { 1 - 2 } Educational qualification & & & \\
\cline { 1 - 2 } Secondary degree in nursing & $38.9000 \pm 3.95671$ & \\
\cline { 1 - 2 } Technical degree in nursing & $37.0000 \pm 6.24500$ & \multirow{2}{*}{0.456} & \multirow{2}{*}{$>0.05$} \\
\cline { 1 - 2 } Bachelor degree in nursing & $35.4022 \pm 4.31980$ & \\
\cline { 1 - 2 } Postgraduate & $38.6000 \pm 2.70185$ & \\
\cline { 1 - 2 } Years of experience & $36.5714 \pm 3.93156$ & & \\
\cline { 1 - 2 } 1-<5 & $36.0455 \pm 3.73500$ & & \\
\cline { 1 - 2 } $10-<10$ & $35.2121 \pm 4.56041$ & & \\
\cline { 1 - 2 } & & & \\
\hline
\end{tabular}


Head Nurses' Attitude and Preparedness Regarding Delegation and its

Relation to Their Performance at Benha University Hospital

\begin{tabular}{|c|c|c|c|}
\hline$>15$ & $36.0882 \pm 4.93821$ & & \\
\hline Marital status & & \multirow[t]{5}{*}{1.98} & \multirow[t]{5}{*}{$>0.05$} \\
\hline Single & $33.8333 \pm 2.31661$ & & \\
\hline Married & $35.8500 \pm 4.43898$ & & \\
\hline divorced & $40.0000 \pm 2.82843$ & & \\
\hline Widow & $41.0000 \pm 1.41421$ & & \\
\hline Training course & & \multirow{3}{*}{0.569} & \multirow[t]{3}{*}{$>0.05$} \\
\hline Yes & $36.6250 \pm 3.55668$ & & \\
\hline No & $35.7872 \pm 4.51966$ & & \\
\hline
\end{tabular}

Table (5): Associative relation between head nurses ' characteristics and their preparedness scores regarding delegation $(n=110)$

\begin{tabular}{|c|c|c|c|}
\hline Characteristics & Mean \pm SD & F test & P value \\
\hline Age in years & & \multirow[t]{4}{*}{0.666} & \multirow[t]{4}{*}{$>0.05$} \\
\hline $20-25$ & $64.2000 \pm 2.94958$ & & \\
\hline $26-30$ & $63.6207 \pm 3.89518$ & & \\
\hline$>30$ & $62.6316 \pm 4.94461$ & & \\
\hline \multicolumn{2}{|l|}{ Educational qualification } & \multirow[t]{5}{*}{2.25} & \multirow[t]{5}{*}{$>0.05$} \\
\hline Secondary degree in nursing & $64.9000 \pm 6.99921$ & & \\
\hline Technical degree in nursing & $63.6667 \pm 5.50757$ & & \\
\hline Bachelor degree in nursing & $62.5109 \pm 4.27488$ & & \\
\hline Postgraduate & $67.0000 \pm 2.12132$ & & \\
\hline \multicolumn{2}{|l|}{ Years of experience } & \multirow[t]{5}{*}{0.344} & \multirow[t]{5}{*}{$>0.05$} \\
\hline $1-<5$ & $63.5714 \pm 3.12364$ & & \\
\hline $5-<10$ & $62.8636 \pm 5.09244$ & & \\
\hline $10-<15$ & $62.3636 \pm 4.70251$ & & \\
\hline$>15$ & $63.2353 \pm 5.08151$ & & \\
\hline \multicolumn{2}{|l|}{ Marital status } & \multirow[t]{5}{*}{1.36} & \multirow[t]{5}{*}{$>0.05$} \\
\hline Single & $59.8333 \pm 4.07022$ & & \\
\hline Married & $63.0500 \pm 4.60868$ & & \\
\hline divorced & $66.0000 \pm 4.24264$ & & \\
\hline Widow & $65.0000 \pm 5.65685$ & & \\
\hline \multicolumn{2}{|l|}{ Training course } & \multirow{3}{*}{0.044} & \multirow[t]{3}{*}{$>0.05$} \\
\hline Yes & $63.1875 \pm 3.58178$ & & \\
\hline No & $62.9255 \pm 4.78402$ & & \\
\hline
\end{tabular}

Table (6): Associative relation between head nurses' characteristics and their performance scores regarding delegation process 
Head Nurses' Attitude and Preparedness Regarding Delegation and its
Relation to Their Performance at Benha University Hospital

\begin{tabular}{|c|c|c|c|}
\hline Characteristics & Mean \pm SD & F test & $P$ value \\
\hline Age in years & & \multirow[t]{4}{*}{0.251} & \multirow[t]{4}{*}{$>0.05$} \\
\hline $20-25$ & $72.4000 \pm 5.07937$ & & \\
\hline $26-30$ & $70.4483 \pm 4.44479$ & & \\
\hline$>30$ & $70.1842 \pm 7.58720$ & & \\
\hline \multicolumn{2}{|l|}{ Educational qualification } & \multirow[t]{5}{*}{0.321} & \multirow[t]{5}{*}{$>0.05$} \\
\hline Secondary degree in nursing & $69.5000 \pm 3.20590$ & & \\
\hline Technical degree in nursing & $73.3333 \pm 2.51661$ & & \\
\hline Bachelor degree in nursing & $70.2717 \pm 7.22952$ & & \\
\hline Postgraduate & $71.8000 \pm 4.76445$ & & \\
\hline \multicolumn{2}{|l|}{ Years of experience } & \multirow[t]{5}{*}{1.77} & \multirow[t]{5}{*}{$>0.05$} \\
\hline $1-<5$ & $70.5238 \pm 5.02612$ & & \\
\hline $5-<10$ & $70.4545 \pm 3.68688$ & & \\
\hline $10-<15$ & $72.1818 \pm 5.01532$ & & \\
\hline$>15$ & $68.4118 \pm 9.78904$ & & \\
\hline \multicolumn{2}{|l|}{ Marital status } & \multirow[t]{5}{*}{0.061} & \multirow[t]{5}{*}{$>0.05$} \\
\hline Single & $71.5000 \pm 1.22474$ & & \\
\hline Married & $70.2900 \pm 7.09146$ & & \\
\hline divorced & $70.0000 \pm 1.41421$ & & \\
\hline Widow & $70.5000 \pm .70711$ & & \\
\hline \multicolumn{2}{|l|}{ Training course } & \multirow{3}{*}{0.325} & \multirow[t]{3}{*}{$>0.05$} \\
\hline Yes & $71.2500 \pm 3.80351$ & & \\
\hline No & $70.2021 \pm 7.15809$ & & \\
\hline
\end{tabular}

Table (7): correlation between head nurses' attitude, preparedness and performance scores regarding delegation process and their working years of experience (hospital and positio

\begin{tabular}{|l|c|c|c||}
\hline \multirow{2}{*}{ Variables } & $\begin{array}{c}\text { Correlation } \\
\text { test }\end{array}$ & years of work in this position & $\begin{array}{c}\text { years of work in this } \\
\text { hospital }\end{array}$ \\
\hline \multirow{2}{*}{ Attitude } & $\mathbf{r}$ & .095 & .073 \\
\cline { 2 - 4 } & P value & .326 & .448 \\
\hline \multirow{2}{*}{ Preparedness } & $\mathbf{r}$ & .075 & .006 \\
\hline \multirow{2}{*}{ Performance } & P value & .433 & .951 \\
\cline { 2 - 4 } & $\mathbf{r}$ & -.048 & -.096 \\
\cline { 2 - 4 } & P value & .617 & .316 \\
\hline
\end{tabular}

** Correlation is significant at the 0.01 level. 


\section{Head Nurses' Attitude and Preparedness Regarding Delegation and its Relation to Their Performance at Benha University Hospital}

Table (8): Correlation between head nurses' attitude, preparedness and performance scores regarding delegation process

\begin{tabular}{|l|c|c|c|c|}
\hline \multicolumn{1}{|c|}{ variables } & Correlation test & Attitude & Preparedness & Performance \\
\hline \multirow{2}{*}{ Attitude } & $\mathbf{r}$ & 1 & $.469^{* *}$ & .110 \\
\cline { 2 - 5 } & P value & & .000 & .251 \\
\hline \multirow{2}{*}{ Preparedness } & $\mathbf{r}$ & $.469^{* *}$ & 1 & .054 \\
\cline { 2 - 5 } & $\mathbf{P}$ value & .000 & & .576 \\
\hline \multirow{2}{*}{ Performance } & $\mathbf{r}$ & .110 & .054 & 1 \\
\cline { 2 - 5 } & P value & .251 & .576 & \\
\hline
\end{tabular}

** Correlation is significant at the 0.01 level (2-tailed).

\section{Discussion}

Head nurses are responsible for the nursing processes and outcomes of patient care. This requires management and delegation skills. Delegation is essential in effective teamwork, it could be a great benefit to improve the delegation skills of the head nurse. Good delegation skills can have a positive effect on teamwork and job satisfaction, provide the head nurse with more time to perform their professional role. Effective delegation may reinforce job satisfaction, responsibility, and productivity, as well as the personal and professional growth of staff (Karnested and Bragadottir, 2012).

The attitude of head nurses regarding

delegation In

relation to head nurses' attitudes, the result of this study found that more than half of head nurses had a positive attitude regarding delegation, it may be due to the majority of head nurses gave clear instruction when they delegate, get upset when the task delegated isn't done right, they would delegate more if they were more confident in delegating, they would delegate more but the tasks they delegate never seem to get done by the way they want to be done and they would delegate more if they have more confident in delegatee. While less than half of them had an uncertain attitude, it may be due to less than half of head nurses disagree that the delegation does not save any time. This finding could be attributed to that; the head nurses lack selfconfidence in their subordinates.

These findings are consistent with Karnested and Bragadottir (2012) who found that overall results on participants' attitude towards delegation are positive. However, these findings are inconsistence with the earlier findings with Gassas et al., (2017), where participants reported unsure attitude regarding delegation. Also, Baddar et al., (2016) and Mohammadi et al., (2013) study are inconsistency with the present study results and they found that nurse managers' attitude towards delegation was neutral.

\section{In relation to the preparedness of} head nurses to delegate effectively

The findings indicated that head nurses' preparedness towards delegation was high. It may be due to the majority of head nurses make clear who do the task in delegation, take into account staff 's individual skills prior to delegation, make clear when, 


\section{Head Nurses' Attitude and Preparedness Regarding Delegation and its Relation to Their Performance at Benha University Hospital}

where, how, and why to do the task in delegation, make clear which the tasks will be delegated in delegation, seek to take comments from delegatee to improve their delegation skill, give delegatee comments following delegation results and seek to take comments from delegatee on whether the task was explained sufficiently.

The current result is congruent with Gassas et al., (2017) who found that participants were competent and ready to delegate. While inconsistent with Baddar et al., (2016) and Karnested and Bragadottir (2012), study that revealed that nurse manager's preparedness towards delegation was positive, and to some extent prepared for effective delegation, but they in need of strengthening their delegation skills.

\section{Relation between head nurses' characteristics and their attitude scores regarding delegation process}

In respect of head nurses attitudes and their characteristics, the findings revealed that there were no significant relation between several characteristics including age, years of experience, marital status and having training course ( $p>0.05)$, therefore, characteristics were not a good indicator for head nurses' attitude towards delegation. Supporting this finding Baddar et al., (2016), who revealed that all the personal and work related characteristics were not a significantly predictor on nurse managers' attitude towards delegation.

On other hand, Kaernested and Bragadottir (2012) reported a relation between age and delegation that older nurses were more comfortable with the delegation and younger nurses and recent graduates often feel uncomfortable to delegation. There was a significant relation between head nurses characteristics and their educational qualification $(p<0.05)$. This result is supported by Gassas et al., (2017) who reported a relations between educational level and delegation. Additionally, Ruff (2011) confirmed the relationship between delegation and education, observing that education is key to ensuring proper delegation.

\section{Relation between head nurses' characteristics and their preparedness scores regarding delegation process}

The current study showed that there was no significant relation between characteristics and head nurses' preparedness to delegate. That illustrates there was no effect of characteristics on head nurses' preparedness to delegate. The current study was inconsistency with Baddar et al., (2016) who showed an only significant relation between nationality, years of experience and nurse manager's preparedness to delegate .

\section{Head nurses' performance regarding delegation process}

Findings of this study showed that the majority of head nurses had satisfactory performance regarding delegation process. This result may be indicated that their performance regarding delegation process is a good performance. Also, this result may be due realize of head nurses about importance of delegation process. In addition, the majority of head nurses receiving training courses about delegation that improve their knowledge and skills about delegation.

This finding agrees with Mikhemer et al., (2016) who found that above twothirds of head nurses had satisfactory performance related to delegation process and agrees with, Kaernested and Bragadottir (2012) who found that the majority of participants 


\section{Head Nurses' Attitude and Preparedness Regarding Delegation and its Relation to Their Performance at Benha University Hospital}

indicated that they were relatively confident regarding their performance toward delegation process. This finding is inconsistent with Diab et al., (2008) who found that more than three fourths of participants had inadequate performance .

Correlation between head nurses'
attitude, preparedness and
performance scores regarding
delegation process and their
working years of [experience.

This study revealed that there was a high significant correlation between head nurses' attitude, preparedness, and performance regarding delegation process and their working years of experience, it may be due to background of head nurses about the more experienced nurse achieve the task quickly than a less experienced one. This result is congruent with the result of Baddar et al., (2016) who revealed a significant correlation between the total number of years of experience and nurse manager's preparedness to delegate. Also, Kaernested and Bragadottir (2012) showed that previous experience and education of participants on delegation are significantly related to attitude and preparedness.

\section{Correlation between head nurses' attitude, preparedness and performance scores regarding delegation process}

This study revealed that there was a high significant correlation between head nurses' attitude, preparedness, and performance regarding delegation process. It may be due to more than half of head nurses had positive attitude, majority of them had high level of preparedness, and majority of them were satisfactory performance regarding delegation process. This result is congruent with the study of Gassas et al., (2017) who revealed that attitudes and competency are decidedly related to each other .

Eschak et al., (2013)who mentioned that effective delegation which promotes safe, quality outcomes for patients and improves the benefits of a delegation of the head nurses, subordinates, and the health care system. Morover, Kaernested and Bragadottir (2012) who found that attitudes and competency were the basis of the delegation.

Effective delegation is an essential component of a head nurse job. It is a critical leadership skill for improving the efficiency and motivation of supervisors and staff. Head nurses must empower staff and hold them more accountable. They must be able to maximize staff knowledge and experience to get the desired results (Smith, 2012).

\section{Conclusion}

In the light of the foregoing present study results, it can be concluded that more than half of head nurses had a positive attitude, while less than half had an uncertain attitude. Also, the majority of head nurses had high preparedness regarding delegation process. The majority of head nurses' performance regarding delegation process were satisfactory. Meanwhile, there was a highly significant correlation between head nurses' attitude, preparedness and performance regarding delegation process. These findings answer all research questions.

\section{Recommendations}

In the light of the findings obtained from the present study, the following recommendations are suggested:

- Workshops and seminars should be held to raise head nurses' awareness about delegation that help to improve their attitude and 


\section{Head Nurses' Attitude and Preparedness Regarding Delegation and its Relation to Their Performance at Benha University Hospital}

focus on increase training and education about scope of nursing practice, increase knowledge, skills and nursing principles, solve problems with delegatee, encourage team work and develop trust in the capabilities of their staff.

- Encourage head nurses about important of evaluation and follow up.

- Head nurse create positive work environment that facilitate the delegation process through good communication, motivation, conflict resolution, negotiation, team work, trust.

\section{References}

American Nurses Association, (2017): Delegation, Retrieved from

https://www.nursingworld.org/pra

ctice-policy/nursing-

excellence/official-position-

statements/.

Baddar, F., Salem, A., and Hakami, A., (2016): Nurse Manager's Attitudes and Preparedness Towards Effective Delegation in Saudi Hospitals, Health Science Journal, Vol.10, No.3,P.2.

Clement, N., (2016): Essentials of Management of Nursing Service and Education, $2^{\text {nd }}$ ed., Jaypee brothers medical , kundi.

Demers , J., (2015): Seven strategies for delegation better and getting more done. Retrieved from http://www.inc.com/iaysondemers/7-strategies-to-delegatebetter-and-get-more-done.htmi

Diab, G., Mohsen , M., Waheeda,S., and Adam,S., (2008): Training as a mean for improving head nurses performance in relation to the delegation function at Shebien El- kom Hospitals. In an unpublished Doctorate thesis, Faculty of Nursing, Menoufiya University.

Engard , B., (2017): Tips to Master Delegation in Nursing , Dissertations, Rivier University on Line, Available at http:// on line.rivier.edu/master-delegationin -nursing.

Eschak,C., Donald,C., and Young,L., (2013): Delegation: A Core Competency for the Graduate Nurse, Master's thesis, The faculty of Human and Social Development, University of Victoria, Pp.33.

Gassas, S., Mahran, M., and Banjar, I., (2017): Nurse Managers' Attitude and Competency Towards Delegation in Jeddah City. American Journal of Nursing Science, 6 (2), Pp.7273.

Hughes, M., (2017): Nurses Storied Experiences of Direction and Delegation, Dotoral degree of Philosophy in Health Sciences, University of Canterbury, Pp.1920.

Innes , J., (2017) : What is your Attitude to delegation?, Retrieved from http :// www.cvcentre.co.uk/ careersadvice / interview-preparationhelp/ what is your attitude-todelegation.

Kaernested,B., and Bragadóttir,H., (2012) : Delegation of Registered Nurses Revisited: Attitudes towards Delegation and Preparedness to Delegate Effectively, Nordic Journal of Nursing Research ,SAGE Publications, vol. 32, 1: pp. 1015.

Mekhimr, E., Elsayed, K., Zahran,S., (2016): Head 


\section{Head Nurses' Attitude and Preparedness Regarding Delegation and its}

Relation to Their Performance at Benha University Hospital

Nurses' Performance Regarding

Delegation Process. In an unpublished Master thesis, Faculty of Nursing, Tanta University.

Mohammadi, Sh., Haghighi,S., and Asteneh, A., (2013) : Attitude of Nursing Managers About Delegation in karaj social security clinics and hospitals, Modern Care Journal, 9 (3) , P.1.

National Council of State Boards of Nursing, (2016): National Guidelines for Nursing Delegation, Journal of Nursing Regulation, 7 (1), P.1.

Ruff, A., (2011): Delegation Skills: Essential to the Contemporary Nurse, Master's Thesis, Graduate Program Faculty, ST. Catherine University, Pp. 6-8.

Sayani, H., (2016): Delegation, a Strategy to Prepare Second Line Nursing Management in Health Care Setting. International journal of Innovative Research and Development,vol.5, Issue.13 , Pp.149-150.

Smith, C., (2012): Recognizing the Need For, Impacts and Benefits of Effective Delegation in The Work Place, Graduate Research Thesis, Senior Service College Fellowship, Defense Acquisition University, Pp.2-7

Swai, L., (2014) : Factors Inhibiting Effective Delegation in Public Organization : A Case Study of Kibaha Education Center (KEC) , Master's degree, The school of Public Administration and Management, Mzumbe University, Pp .1,6,9.

Zakaria, A., (2016): Effectiveness of Learning Module on Time Management Ability and
Delegation Skills for Head Nurses, IOSR Journal of Nursing and Health Science, 5

(2), Pp.31-40. 